\title{
Image findings of Vogt-Koyanagi-Harada
}

\section{Achados de imagem da síndrome de Vogt-Koyanagi-Harada}

Nivaldo Borges Nunes Júnior', Graciane Bertolo², Lázaro Luís Faria do Amaral³, Sílvia Marçal Benício de Mello ${ }^{4}$

Female patient, 22 years old, presented complaining of blurred vision, bilateral tinnitus and hearing loss on the left.

Ophthalmologic evaluation showed signs of bilateral uveitis, and otorhinolaringologist evaluation pointed minimal hearing loss on the left.

Imaging tests helped to confirm the diagnosis of Vogt-Koyanagi-Harada (VKH) and evaluation of disease involvement ${ }^{1-3}$.

The diagnosis of VKH syndrome is clinical and confirmed by imaging. It is one of the only diseases that provide
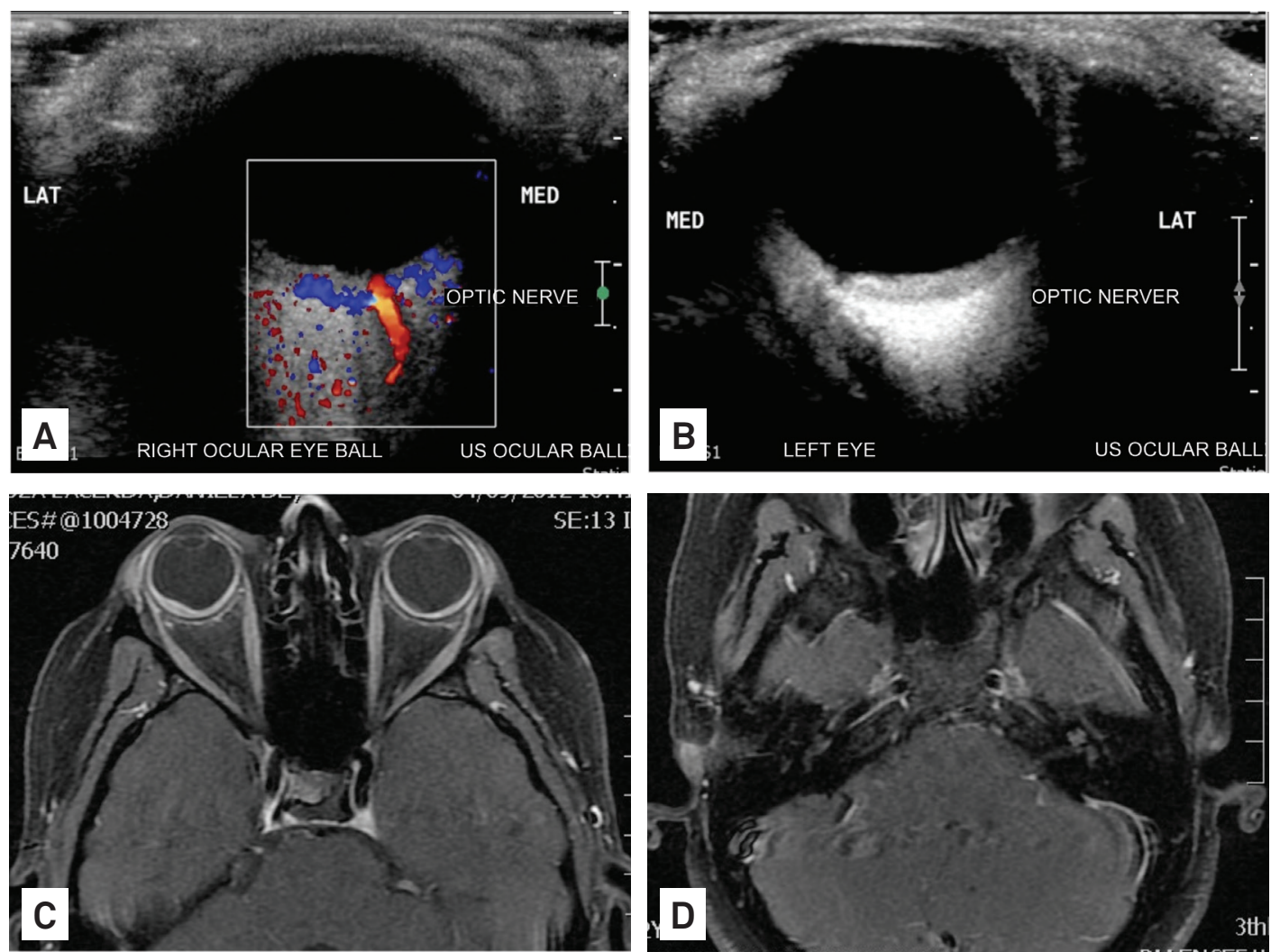

Fig 1. (A) and (B) Ultrasound (USG) of the eyeballs: increased vascularization and thickening of the posterior choroidal eyeballs. (C) and (D) Magnetic resonance imaging (MRI) of the brain and orbits. (C) Thickening and impregnation by gadolinium anomaly in the posterior aspect of the eyeballs, suggestive of uveitis. (D) Impregnation anomalous bilateral membranous labyrinth, suggestive of labyrinthitis.

Study carried out in Medlmagem, Portuguese Beneficent Hospital of São Paulo, São Paulo SP, Brazil.

${ }^{1}$ Fellow in Neuroradiology and Imaging of the head and neck of Medlmagem, Portuguese Beneficent Hospital of São Paulo, São Paulo SP, Brazil;

${ }^{2}$ Medical student of the Radiology department of Medlmagem, Portuguese Beneficent Hospital of São Paulo, São Paulo SP, Brazil;

${ }^{3}$ Chief of Neuroradiology service of Medlmagem, Portuguese Beneficent Hospital of São Paulo, São Paulo SP, Brazil;

${ }^{4}$ Radiologist of Medlmagem, Portuguese Beneficent Hospital of São Paulo, São Paulo SP, Brazil.

Correspondence: Nivaldo Borges Nunes Júnior; Rua José Getúlio 192 / apto. 303;01509-001 São Paulo SP - Brasil; E-mail: nivaldo01@hotmail.com Conflict of interest: There is no conflict of interest to declare.

Received 02 September 2012; Received in final form 28 March 2013; Accepted 05 April 2013. 


\section{References}

1. Matiello M, Carvalho HC, Alvarenga $H$, et al. Vogt-KoyanagiHarada. Cad Bras Med 2004;17:50-58.

2. Gonçalves CS, Lim SD, Pezzin PAC, et al.Vogt-Koyanagi-Harada syndrome:
Review of literature. Architect Otorrinolaringol Int 2008;12:419-425.

3. Alves MLA, Borges AS. Vogt-Koyanagi-Harada and his multisystemic involvement. Rev Assoc Med Bras 2010;56:590-595. 